\title{
Experiences of medical and pharmacy students' learning in a shared environment: A qualitative study
}

\author{
D Johnston, ${ }^{1}$ BPharm, MPharm; P A McInerney, ${ }^{2}$ PhD; O Fadahun, ${ }^{2}$ MSc (Med), MB BS; L P Green-Thompson, ${ }^{2}$ MMed (Anaesthesia), MB BCh;
} S Moch, ${ }^{1}$ MEd, MSc (Med), BSc (Hons), BPharm; P Goven Shiba, ${ }^{1}$ MB BCh, BSc (Hons) Pharmacology; A Magida, ${ }^{2}$ BSocSci (Hons)

${ }^{1}$ Department of Pharmacy and Pharmacology, School of Therapeutic Sciences, Faculty of Health Sciences, University of the Witwatersrand, Johannesburg, South Africa

${ }^{2}$ Centre for Health Science Education, Faculty of Health Sciences, University of the Witwatersrand, Johannesburg, South Africa

Corresponding author: D Johnston (deanne.johnston@wits.ac.za)

Background. Patient care is significantly affected by doctors and pharmacists, who have specialised knowledge and skills. In establishing an interprofessional undergraduate learning environment, medical and pharmacy students have the opportunity to start working in a collaborative manner early on in their careers.

Objectives. To implement combined clinical visits, where medical and pharmacy students jointly encounter patients, and to establish the students' perceptions of working in an interprofessional team.

Methods. Final-year pharmacy students together with third-year medical students at the University of the Witwatersrand, Johannesburg, South Africa were invited to participate in weekly joint patient encounters at a central academic hospital from May to July 2012. Students assessed patient records and participated in the patient consultation, guided by the supervising doctor. Participants from each discipline were invited to attend a disciplinespecific focus group discussion, where they shared their perceptions and experiences. The discussions were audio-taped and transcribed verbatim. Content analysis was used to analyse the transcriptions. Ethics approval was obtained from the Human Research Ethics Committee of the University. Results. Four themes were identified: the meeting of professions; shared teaching and learning; reciprocity in teaching and learning; and valuing the experience. It is evident that there was a change in students' attitudes, and they developed mutual respect and a better understanding of their professional role and that of their peers. They also reported positive experiences in learning from and with one another.

Conclusion. This study focused on eliciting students' perceptions and attitudes towards interprofessional teaching and learning. The positive responses to the experiences suggest that further learning opportunities should be created with students from another discipline.

Afr J Health Professions Educ 2015;7(2):183-186. DOI:10.7196/AJHPE.394

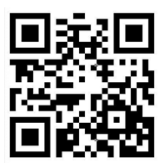

Interprofessional education is central to the development of collaborative practice among healthcare professionals. ${ }^{[1]}$ It 'occurs when two or more professions learn with, from and about each other to improve collaboration and the quality of care' and includes the training of undergraduate students from different disciplines working together in a learning environment. ${ }^{[2]}$

Collaborative learning between healthcare professionals improves the efficiency of the healthcare system through shared integration of skills and knowledge. It also leads to the development of mutual respect and identifies new roles and responsibilities of team members. ${ }^{[3]}$ The promotion of an interprofessional undergraduate learning environment offers health science students an opportunity to work in a collaborative manner early on in their careers. This co-operative setting may prevent stereotyped and negative attitudes that students may develop towards other professions. ${ }^{[4]}$

Doctors and pharmacists have specialised knowledge and skills, with the common goal of improving patient care. Relationships between these two professions can be strengthened by means of collaboration. ${ }^{[5]}$ Studies involving interprofessional education of medical and pharmacy students are limited; however, available outcomes indicate that there are benefits to joint learning opportunities, e.g. learning to work in a team. ${ }^{[6-8]}$

The University of the Witwatersrand's Faculty of Health Sciences, Johannesburg, South Africa (SA) offers undergraduate degree programmes in six health professions. This provided an opportunity to instigate interprofessional encounters of patient care between pharmacy and medical students to establish students' perceptions of working together.

\section{Methods}

\section{Organisation of the patient encounter}

The study took place at one of the large tertiary teaching hospitals associated with the University. In the current system, the medical students attend weekly clinical practice days while the pharmacy students are assigned to the hospital dispensary. Medical students were expected to elicit a patient history and conduct an examination before presenting their findings to the attending doctor during a bedside tutorial. The pharmacy students, however, during their time in the dispensary, participated in stock procurement, extemporaneous compounding, dispensing of medication and patient counselling.

For the purpose of this study, all the participating students were registered at the University of the Witwatersrand and the supervising staff members were employed jointly by the Faculty of Health Sciences and the Department of Health. Fifteen groups were formed, each consisting of a final-year pharmacy student and 2 third-year medical students, to learn clinical skills, history taking and examination as well as discussing the pharmacological management of the patient. Rather than going to the dispensary, the pharmacy students attended medical student clinic rounds and participated in the patient clerking process and ensuing tutorial.

The joint clinical groups participated in weekly visits to the wards between May and July 2012. These groups were assigned to wards as per the normal rotation of the medical students involved. Working as a group, the students were expected to assess patient records and participate in patient consultation, guided by the supervising doctor. Because of the opportunistic 
nature of the clinical learning environment, learning outcomes were not specified for each week.

\section{Focus groups}

Students who participated in the encounter were invited to attend disciplinespecific focus group discussions, where they could share their perceptions and experiences. Informed consent was obtained for study participation and audio-recording. The discussions were conducted in a room where privacy could be ensured and the 2 groups were asked the same primary questions (Table 1) by the interviewers who probed further, depending on the ideas that emerged. The audio-recordings were transcribed verbatim and checked by the researchers for correctness. Tesch's 8 steps were used to guide the data analysis process ${ }^{[9]}$ and common themes were identified.

Table 1. Primary questions asked in each of the discipline-specific focus groups

1 From your perspective, describe the experience of multidisciplinary learning

2 What were the benefits of the encounter?

3 What were the disadvantages or problems with this kind of learning?

4 Do you feel competent in your professional role to participate in the multidisciplinary encounter?

\section{Results}

Fourteen pharmacy students and 13 medical students participated in each discussion, respectively. There were male and female participants in both groups. The size of the groups did not appear to adversely influence participation in the discussion. Four themes emerged from the data, i.e. the meeting of professions; shared teaching and learning; reciprocity in teaching and learning; and valuing the experience.

\section{The meeting of professions}

This theme was characterised by descriptions of learning to evaluate other professions and understand their contribution to healthcare. This appreciation of others resulted in a changed perception of roles. One pharmacy student stated 'It's like the professions almost don't meet', describing the interaction between the pharmacy and medical student before the interprofessional encounter. A medical student intimated that there is a perception that the hospital environment was more their 'domain' than that of the pharmacy students. A pharmacy student stated that they felt 'like parasites to them [medical students]; like they are going [on] with their normal routine and we are just on the side. The pharmacy students relayed comments made by medical students that '[a] pharmacist should become doctors' secretaries; it's convenient to have them around'. When the medical students described their initial relationship they indicated that the pharmacy students at first seemed 'shy' and that they sensed the pharmacy students may have felt inferior to them. Furthermore, a medical student mentioned that 'medical students sometimes almost tend to give off more superior attitudes'. However, as time progressed, pharmacy students commented that 'very good relationships' were formed with the medical students and that 'mutual respect was a very very important aspect that came to light?.

Learning professional roles was discussed in a range of thoughts and ideas. Gaining understanding of each other's roles led to a changed perception and was valued: 'I enjoyed the fact that we gained respect for one another.' Pharmacy students identified their role in the interprofessional encounters as they described two occasions when they had identified an anomaly with the patient's medication and brought it to the attention of the attending doctor. Furthermore, a pharmacy student found an opportunity to counsel a patient on the correct usage of an asthma pump.

Gaining understanding of each other's curricula contributed to valuing the other profession - a participating medical student stated: '[it showed] me just like how much they are learning as pharmacists. Like they were telling us what they actually study in their degree and you know it just made me realise just how much [more] they know, than I thought.' The medical students thought that it would be a good idea to have learning opportunities with other professionals, such as physiotherapists, occupational therapists and nursing students.

Taking the shared learning into the postgraduate area, one of the medical students stated that 'maybe interns could benefit perhaps from a roaming pharmacist, because they have all the pharmacology knowledge and as interns you're still learning so much ... I don't know cos I'm not there but I think it could be quite useful to have a pharmacist who could come into [the] wards and help you with the prescribing.

\section{Shared teaching and learning}

There were mixed views in both focus groups with regard to the level of shared learning and teaching. The most commonly expressed view was that the teaching and learning experiences were shared, and that each group of students contributed to and benefited from the exercise. A medical student's perspective was that '[the pharmacy students] were always willing to learn and always go to the tuts [tutorials] with us, they even wanted to [do] clinical skills with [us] and asked us things. So we were always teaching them and they were teaching us back.' This perspective was endorsed by some of the pharmacy students, with one stating that 'I learnt a lot about taking a proper patient history from my colleague who was a medic student, and she learnt from me when I was going through the medication with her, what it's for and why shouldn't you give it to this patient'.

A minority of students, however, were at variance with this interpretation. The medical students expressed the view that the pharmacy students imparted their knowledge about drugs, but gained little in return. These views were expressed as follows: 'No, I don't think I taught them anything or we did. I think they taught us all the drugs.' And another confirmed that 'they never once asked us "what is this disease?", never once. So for me it was more of a case of they were teaching us, I don't know what they gained from it. This was not the view of all the medical students. One of the pharmacy students expressed her disappointment at the asymmetry of her learning experience compared with that of the medical students, saying 'I couldn't wait meeting the medical students but personally I found that they ... they learned more. I feel I could have benefited more.'

While many of the pharmacy students were enthusiastic about the opportunities that they were afforded to learn clinical skills, their main dissatisfaction arose from the perception that the focus of the hospital day at third-year level for the medical students was in developing sufficient clinical acumen to be able to correctly diagnose a patient's ailment. The pharmacy students would have preferred an emphasis on therapeutic management. One of the students felt that 'the clinical aspect of it was much more dominant and [the] pharmacological side was much less covered' (referring to the teaching input). 


\section{Reciprocity in teaching and learning}

Students acknowledged that the process of teaching assisted them in their own development of knowledge and skills. A medical student stated: 'I found that the most helpful aspect of this experience for me, was the fact that we were kind of instructing or teaching as it were the pharmacology students in our clinical things that we were doing, and so that obviously helps you to learn quite a lot when you're instructing someone else. That was probably the most beneficial part that I found.'

The medical students observed that the pharmacy students contributed drug information, specifically with regard to generic drug names, trade names, recognition of adverse effects and sourcing of drug information. They also improved the speed at which the preparation sessions occurred, as they provided a faster source of information than the medical students, who had to refer back to their notes. One medical student reflected that 'I think the best learning experience for both pharmacy students and medical students was the time we went through the patient files - that whole process was sped up so much. We would have trouble with the drugs, specifically with trade names and they help there by far with the whole experience in those settings.'

The medical students felt that they were able to teach clinical skills to the pharmacy students and explain the background pathology and microbiology to them to assist in developing their understanding of the patients' problems. This reciprocal teaching was expressed as follows: 'For me it was pretty helpful because my pharmacy student had an assignment of taking patient history and examination and I had an OSCE coming up, so I was kind of practising and teaching him and we were helping each other.'

\section{Valuing the experience}

Students ascribed value to the experience of peer learning as they felt able to question and argue with their student colleagues in constructing their own understanding. They thought that explanations were less complicated and the whole learning situation was simplified compared with when they were taught about drug therapy by a staff member who was hierarchically superior. This ability to construct knowledge through discussion was described as follows: 'It's nice hearing all of this information from someone who is your peer as well, it's easier too, I don't know if I'm not sure or disagree, I find it easier to sort of argue with them and then let's just say come to a conclusion, it's easier to do that with a peer than someone who is considered your superior'. Another medical student described this benefit, saying that 'clinicians are really advanced. They just say this is how it works and that is what we expect.'

While the medical students valued the drug information provided by the pharmacy students, they also valued the resources that the pharmacy group provided: 'My pharmacology student had a SAMF [South African Medicines Formulary] - so that was probably the most useful part.'

The long-term value of the experience extended beyond the allocated time period to enrich other learning. This was expressed by a medical student who noted that 'it was nice to have someone to talk to throughout the block, not necessarily just on hospital days. I had formed quite a good relationship with my student and I was able to ask her questions I had regarding pharmacology we were doing.

\section{Discussion}

This study was the first of its kind at the University of the Witwatersrand, involving undergraduate medical and pharmacy students participating in joint patient encounters. These two professional disciplines traditionally had had little or no student interaction at an undergraduate level. The intervention was largely unstructured, as outcomes were not explicit other than participation in groups in the clinical setting. This may warrant further attention in future efforts in interprofessional learning. The four themes demonstrate positive results. It is evident that there was a change in attitude of the students, the development of mutual respect, a better understanding of their professional role and that of their peers, and positive learning experiences from and with one another. Other studies involving interprofessional undergraduate pharmacy and medical students support our findings. ${ }^{[6,8]}$

Both groups of students noted attitudes related to superiority and hierarchy. For the pharmacy students this was compounded by the fact that they joined the medical students in their 'domain'. Gilbert ${ }^{[10]}$ notes that competition exists between medical practitioners and pharmacists and suggests that each profession appears to need to protect their individual professional rights to diagnose, prescribe and dispense. This may explain the antagonistic relationships that often exist between these two professional groups, which may, in turn, filter down to the students. However, the students described improved understanding of the other profession, and relationships and friendships formed over the course of the intervention. Similarly, O'Neill and Wyness ${ }^{[8]}$ found that students' participation in teams led to relationships being formed among students, deepening their understanding of the professions. Interprofessional activities could assist to 'break down unnecessary barriers' between doctors and pharmacists, ${ }^{[6]}$ as seen in the change of the students' attitude to one another in our study.

Mutual respect was formed between the two groups. The pharmacy students described the development of respect over time between them and the medical students, and they felt that the medical students respected them more when they could see the contribution the pharmacy students could make to their learning. The medical students concurred with this perception when they expressed surprise at the extensive content of the pharmacy curriculum. This development of mutual respect is consistent with one of the principles of interprofessional education described by Parsell and Bligh, ${ }^{[11]}$ i.e. 'respects the integrity and contribution of others'.

Participants in this study noted the varying interests between the two student groups, i.e. the medical students were interested in the examination and diagnosis of the patient's condition, while the pharmacy students were focused on medication. These interests are consistent with how students view their roles in their professions. This concurs with the findings described by Greene et al. ${ }^{[6]}$ who found that medical students were more comfortable with interviewing patients and pharmacy students with drug therapy. The ability to share and gain knowledge and skills in the peer teaching that occurred was clearly described. The medical students found particular value in the pharmacy students' knowledge of the medications prescribed and therefore viewed the pharmacy students as a useful resource. However, fewer pharmacy students spoke about learning from the medical students with regard to taking a patient's history and learning clinical skills. Hall and Weaver ${ }^{[12]}$ note that there is a need for 'overlapping competencies and share[d] responsibilities' for interdisciplinary team collaborations to take place. This may explain the asymmetry in learning expressed by some of the pharmacy students, who had anticipated that they would learn more from the medical students.

Barr et al. ${ }^{[13]}$ describe five levels of educational outcomes that may be identified in interprofessional learning (Table 2). 
Table 2. Modified levels of educational outcomes that result from interprofessional education ${ }^{[13]}$

\section{Level 1: Reaction}

Level 2a: Modification of perceptions and attitudes

Level 2b: Acquisition of knowledge and skills

Level 3: Behavioural change

Level 4: Change in organisational practice

Level 5: Benefits to patients/clients

The findings of our study align with levels 1 and 2 of the outcomes (Table 2). The interprofessional learning experience that we implemented generated a reaction from students, modifying their perceptions and attitudes. Both groups reported to have learnt through the shared experience.

The study was initiated to document a shared learning experience between medical and pharmacy students to incorporate interprofessional clinical training in the undergraduate curricula of the two groups. However, several limitations constrain such generalisation. Compared with the total class sizes from both student groups, only a small number participated in the learning opportunity. Furthermore, as participation in this study was voluntary, students' contribution and performance were not quantitatively measured through assessment. Without placing academic value on participation, students might not place value on the knowledge and skills acquired. ${ }^{[14]}$ Difficulties were experienced in communicating with the supervising doctors; this needs to be addressed in future studies.

\section{Conclusion}

Our study focused on eliciting attitudes and opinions of students to learning through exposure in this interprofessional encounter. We found that students valued this shared experience, which generated a better understanding of each other's profession and facilitated peer teaching and learning. It has been suggested that to measure effectiveness, students' attitudes towards interdisciplinary education should be assessed on entry into the programme, after the clinical component, on completion of the course, and when the graduate is practising as a professional. ${ }^{[15]}$ Future studies should consider outcomes concerning 'changes in behaviour' relating to professional practice, 'change in organisational practice' and 'benefits to patients/clients. ${ }^{[13]}$

\section{References}

1. World Health Organization Study Group on Interprofessional Education and Collaborative Practice. Framework for action on interprofessional education and collaborative practice. 2010. http://whqlibdoc.who.int/hq/2010 WHO_HRH_HPN_10.3_eng.pdf (accessed 6 December 2013).

2. Centre for the Advancement of Interprofessional Education. Interprofessional education. 2013. http://caipe.org uk/about-us/defining-ipe/ (accessed 6 December 2013).

3. World Health Organization. Learning together to work together for health. 1988. http://whqlibdoc.who.int/trs WHO_TRS_769.pdf (accessed 6 December 2013).

4. Parsell G, Spalding R, Bligh J. Shared goals, shared learning: Evaluation of multiprofessional course for undergraduate students. Med Educ 1998;32:304-311. [http://dx.doi.org/10.1046/.1365-2923.1998.00213.x]

5. McDonough RP, Doucette WR. Developing collaborative working relationships between pharmacists and physicians. J Am Pharm Assoc (Wash) 2001;41:682-692.

6. Greene RJ, Cavell GF, Jackson SHD. Interprofessional clinical education of medical and pharmacy students. Med Educ 1996;30:129-133. [http://dx.doi.org/10.1111/j.1365-2923.1996.tb00730.x]

7. Horsburgh M, Lamdin R, Williamson E. Multiprofessional learning: The attitudes of medical, nursing and pharmacy Horsburgh M, Lamdin R, Williamson E. Multiprofessional learning: The attitudes of medical, nursing and pharn
students to shared learning. Med Educ 2001;34:876-883. [http://dx.doi.org/10.1046/.1365-2923.2001.00959.x]

O'Neill BJ. Wyness MA. Student voices on an interprofessional course. Med Teach 2005:27:433-438. [http:// dx.doi.org/10.1080/01421590500086680]
dreswell

9. Cresswell JW. Research Design: Quantitative, Qualitative, and Mixed Methods Approaches. 2nd ed. Thousan Oaks, CA: Sage, 2003.

0. Gilbert L. To diagnose, prescribe and dispense: Whose right is it? The ongoing struggle between pharmacy an medicine in South Africa. Current Sociology 2001;49:97-118. [http://dx.doi.org/10.1177/0011392101049003007]

11. Parsell G, Bligh J. Interprofessional learning. Postgrad Med J 1998;74:89-95. [http://dx.doi.org/10.1136/pgmj.74.868.89]

12. Hall P, Weaver L. Interdisciplinary education and teamwork: A long and winding road. Med Educ 2001;35:867875. [http://dx.doi.org/10.1046/j.1365-2923.2001.00919.x]

13. Barr H, Freeth D, Hammick M, Koppel I, Reeves S. Evaluations of interprofessional education. A United Kingdom review for health and social care. The United Kingdom Centre for the Advancement of Interprofession Education with the British Educational Research Association. 2000. http://caipe.org.uk/silo/files/evaluations-ofinterprofessional-education.pdf (accessed 28 November 2013)

14. Parsell G, Bligh J. Educational principles underpinning successful shared learning. Med Teach 1998;20:522-529. [http://dx.doi.org/10.1080/01421599880229]

15. Gilbert JHV. Interprofessional education for collaborative, patient-centred practice. Nursing Leadership 2005;18:32-38. 